
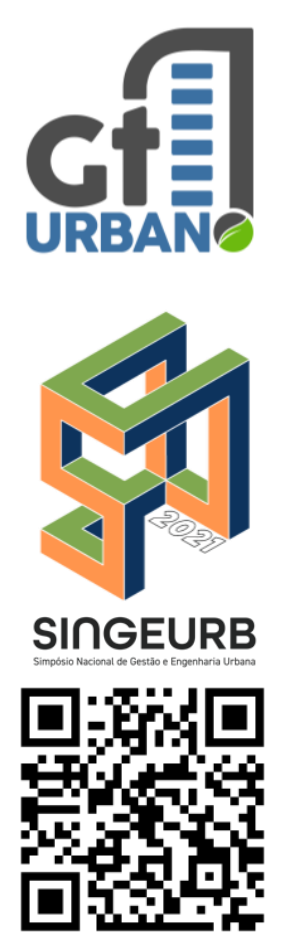

Como citar:

FILHO, Nivaldo Gerôncio da Silva; JACOB, Juliana B.; ARRUDA, Angela Maria. A malha cicloviária como um modal de deslocamento sustentável: (in) adequações, (in) eficiência e (in) segurança - o caso da região central do Recife - PE. In: III SIMPÓSIO NACIONAL DE GESTÃO E ENGENHARIA URBANA: SINGEURB, 2021, Maceió. Anais... Porto Alegre: ANTAC, 2021. p. 370-383.

Disponível em: https://eventos.antac.o rg.br/index.php/singe urb/issue/view/14

\title{
A malha cicloviária como um modal de deslocamento sustentável: (in) adequações, (in) eficiência e (in) segurança - o caso da região central do Recife - PE
}

Cycleview mesh as a mode of sustainable displacement: (in) fitness, (in) efficiency and (in) security - case study of the central region of Recife - PE

Nivaldo Gerôncio da Silva Filho, Universidade Estadual da Paraíba, nivaldo.geroncio.filho@gmail.com

Juliana Bevilacqua Jacob, Universidade Federal de São Carlos, julianajacob@yahoo.com.br Angela Maria Arruda, Universidade Federal de São Carlos, angelaarruda@estudante.ufscar.br

\section{RESUMO}

A questão da mobilidade urbana é, na atualidade, tema central quando nos reportamos às problemáticas vividas nas médias e grandes cidades brasileiras. Não ao acaso, as tentativas de melhoria podem ser observadas em diversos municípios, principalmente naqueles que são municípios-sede (capitais). No entanto, tais tentativas estabelecidas nas diversas gestões, não estão à altura dos problemas que se avolumam no tocante aos deslocamentos e circulação dos bens e serviços. Por outro lado, a saturação do sistema de transporte como um todo, juntamente com suas ineficiências e inadequações, levantam a discussão sobre o conceito de mobilidade urbana sustentável - que diz respeito à priorização dos transportes públicos e, mais precisamente, aos transportes não motorizados - honrosamente traduzidos no deslocamento a pé e através de bicicletas. Nesse contexto, este trabalho teve como objetivo geral destacar a real situação da malha cicloviária na região central e nos bairros circunvizinhos cidade de Recife-PE, com foco, sobretudo, na segurança do ciclista. Para tanto, apresentou um diagnóstico desse modal de deslocamento no contexto atual, com base em informações coletadas in loco a partir de visitas técnicas observacionais, estabelecidas com base em recomendações da literatura e por meio de um levantamento fotográfico. Assim, os resultados não foram satisfatórios e podese concluir que é necessário um reexame nas políticas públicas para este setor e ações mais contundentes no sentido de melhorias.

Palavras-chave: Mobilidade Urbana Sustentável, Infraestrutura, Ciclovia. 


\begin{abstract}
The issue of urban mobility is currently a central theme when we refer to the problems experienced in medium and large Brazilian cities. It is not by chance that attempts at improvement can be observed in several cities, especially in those that are host cities (capitals). However, such attempts established in the various administrations, are not up to the problems that increase with regard to displacement and circulation of goods and services. On the other hand, the saturation of the transport system as a whole, together with its inefficiencies and inadequacies, raise the debate on the concept of sustainable urban mobility - which concerns the prioritization of public transport and, more precisely, non-motorized transport honorably translated into displacement on foot and by bicycle. In this context, this work aimed to highlight the real situation of the cycling network in the central region and in the surrounding neighborhoods of the city of Recife-PE, with a focus, above all, on cyclist safety. To this end, it presented a diagnosis of this modal of displacement in the current context, based on information collected in loco from observational technical visits, established based on literature recommendations and through a photographic survey. Thus, the results were not satisfactory and it can be concluded that a re-examination of public policies for this sector and more forceful actions towards improvements is necessary.
\end{abstract}

Keywords: Sustainable Urban Mobility, Infrastructure, Bike Path.

\title{
1 INTRODUÇÃO
}

A ótica alicerçada, a despeito da amplitude e da complexidade, na seara da mobilidade urbana é bastante ampla e, por vezes, contundente e passível de ampla discussão. No entanto, as atuais contradições em todo sistema de transportes - modais - não advém de um mero acaso, mas sim de fatores múltiplos que se desenvolveram, sobretudo, a partir da década de 1930 e que se acentuaram em meados de 1950. Tal fato pode ser constatado na afirmação a seguir:

No Brasil, em especial, a preferência ao transporte rodoviário começou a ser dada a partir da Constituição de 1934, com o direcionamento dos esforços para construção de rodovias no país. Em 1956, passamos pela introdução da indústria automobilística, acompanhada, desde então, por políticas públicas de apoio aos veículos automotores, em especial ao carro e à motocicleta (RUBIM E LEITÃO, 2013).

No entanto, como já dito anteriormente, no cerne do conceito da mobilidade urbana, há certa amplitude e, por vezes, contradições à medida em que outros fatores podem ser elencados, como o fascínio e desejo da população em prol do transporte privado. Segundo Rubim e Leitão (2013), atualmente, mais de 50\% dos domicílios do Brasil possuem um automóvel ou uma moto em suas garagens. De fato, a frota brasileira de veículos está em franco crescimento, devido à política de incentivos adotada pelo governo desde a década de 1930. Nos últimos dez anos, o número de automóveis no país cresceu 138,6\%, enquanto a população brasileira teve expansão de apenas $12,2 \%$ no mesmo período.

As externalidades dessa mobilidade podem ser destacadas sob outros aspectos, que não só dizem respeito a priorização do automóvel, mas também incidem nas questões ambientais, sociais e econômicas, como podem ser confirmadas a partir da seguinte ideia:

Em pouco mais de seis décadas, o debate em torno das ideias que agregam-se ao conceito da mobilidade urbana mesmo que não associadas diretamente ao termo, têm adquirido uma complexidade bastante acentuada e ao mesmo tempo 
contraditória, dada a multiplicidade de variáveis que nela passa a interferir, tornando-a passível de uma discussão que vai muito além do campo teórico (SILVA FILHO E RAIA JÚNIOR, 2016).

Nesse contexto, com base na ideia dos autores, é possível destacar que, na atualidade, as discussões do tema direcionam-se a dois aspectos inerentes à tais ideias, ou seja, aquele relativo à amplitude que, relaciona-se ao viés histórico, a partir do momento em que o termo ganha ênfase; ao viés econômico, no que se refere à produção interna do país; ao viés ambiental, principalmente a partir de grandes conferências mundiais sobre o meio ambiente; ao viés social, no atendimento inclusivo e essencial à população; e por fim ao viés político, no tocante às tomadas de decisões.

Com foco nessa problemática, o Ministério das Cidades, por meio de seus cadernos de publicação Mcidades de mobilidade urbana 6 - Política Nacional de Mobilidade urbana, (2004), estabeleceu alguns princípios e parâmetros para conceituar a "mobilidade urbana sustentável como sendo um conjunto de políticas e ações que pudessem priorizar os meios de transportes públicos e não motorizados. No entanto, ao se falar em transportes não motorizados, as referências e preocupações se debruçaram na caminhada a pé, em detrimento dos deslocamentos realizados com bicicletas. Nesse sentido, Feder (2005) destaca que, nos últimos anos, a utilização da bicicleta como meio de transporte passou a ser discutida com maior ênfase. Os benefícios da utilização de bicicletas, tanto para os usuários quanto para as cidades são descritos na literatura por diversos autores, dentre os quais Geipot (1980), Neves (2003), Litman (1999) apud Pezzuto e Sanches( 2003).

Embora com pouco incentivo a frota estimada de bicicletas no Brasil, em 2001, era de 48 milhões (Abraciclo, 2004), ou seja, um número bastante significativo. A integração da bicicleta com os demais modais de transporte coletivo, especialmente ônibus e metrô, é apontada como uma das melhores soluções para combater a diminuição contínua de passageiros transportados por quilômetro (Miranda, 2004). Ainda que discretamente, várias iniciativas estão sendo tomadas para facilitar e incentivar o uso da bicicleta nas cidades brasileiras. Este é o caso, por exemplo, das cidades de do estado de Pernambuco, como Recife, Rio Grande do Sul, a exemplos de Porto Alegre e Campo Bom e Santa Catarina com a cidade de Blumenau. Algumas outras cidades já possuem uma estrutura cicloviária mais desenvolvida, como é o caso do Rio de Janeiro, Curitiba e Duque de Caxias (Geipot, 2001b). Em função de seu custo reduzido, a ciclofaixa passou a ser a opção adotada pelas prefeituras para incentivo do uso de bicicletas.

\section{PROCESSO METODOLÓGICO}

A Partindo da ideia principal de uma vistoria técnica que será confrontada com a literatura pertinente Código de Trânsito Brasileiro (CTB) e com as orientações da Associação Brasileira de Normas e técnicas (ABNT). Sob a ótica mais intrínseca da característica dessa pesquisa, o quadro, a seguir, resume de maneira mais clara a técnica, as funções e a abordagem metodológica. 
Quadro 1 - Resumo das características, abordagem e função da metodologia do artigo

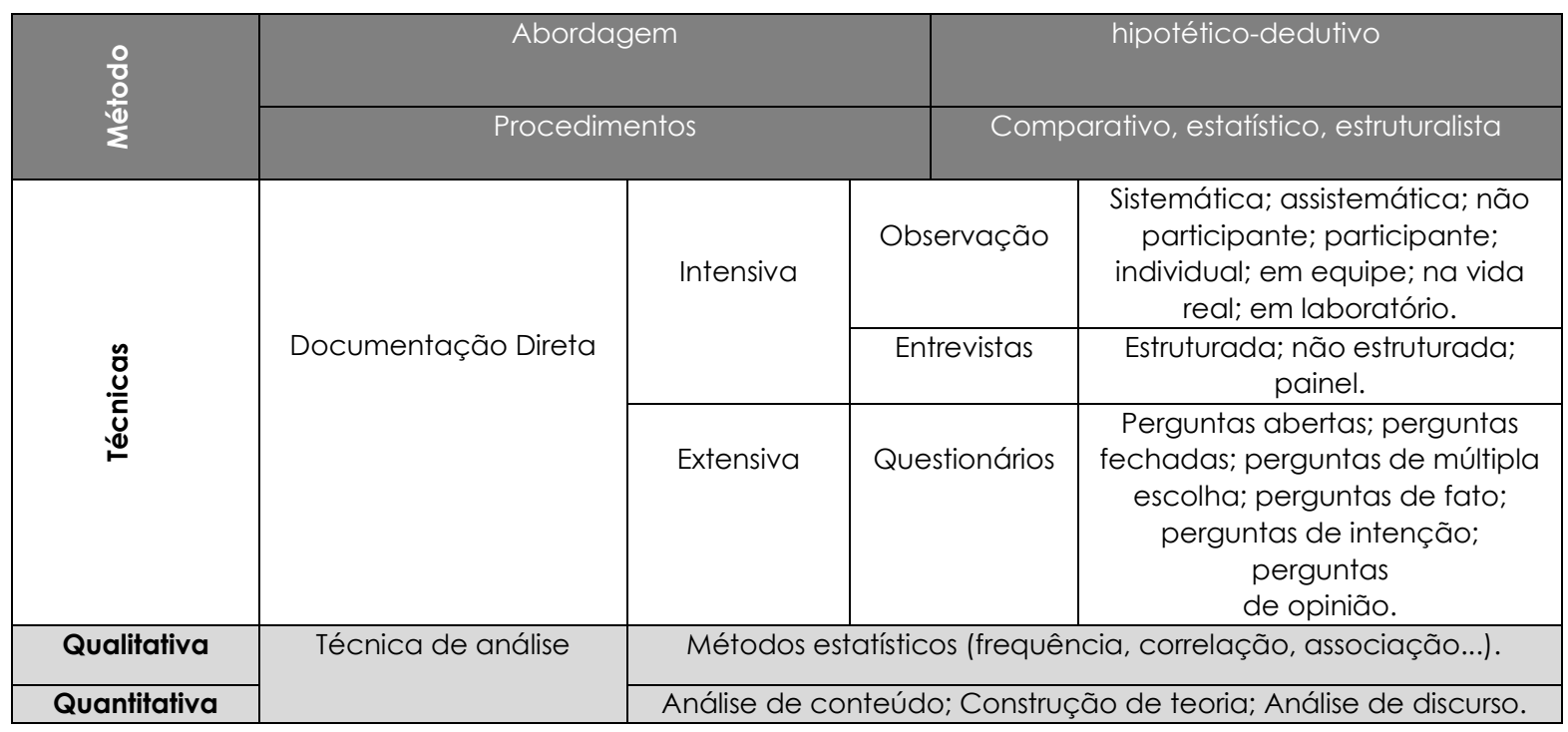

Fonte: Adaptado de Roesch (1999) e Prodanov (2013

Prodanov (2013) destaca que, o método hipotético-dedutivo foi definido por Karl Popper a partir de críticas à indução, expressas em "A lógica da investigação científica", obra publicada pela primeira vez em 1935 (GIL, 2008). A indução, conforme Popper, não se justifica, "pois o salto indutivo de 'alguns' para 'todos' exigiria que a observação de fatos isolados atingisse o infinito, o que nunca poderia ocorrer, por maior que fosse a quantidade de fatos observados" (GIL, 2008, p. 12). Já no tocante ao procedimento, o processo é mais amplo em função da característica da coleta de dados.

No que diz respeito a questão qualitativa e quantitativa foi estabelecida em função de uma análise numérica para aplicar a comportamentos. Ainda sobre o método hipotético-dedutivo inicia-se com um problema ou uma lacuna no conhecimento científico, passando pela formulação de hipóteses e por um processo de inferência dedutiva, o qual testa a predição da ocorrência de fenômenos abrangidos pela referida hipótese. Podemos apresentar o método hipotético-dedutivo a partir do seguinte esquema (GIL, 2008, p. 12):

Problema $\rightarrow$ Conjecturas $\rightarrow$ Dedução de consequências observadas $\rightarrow$ Tentativa de falseamento $\rightarrow$ Corroboração.

O processo de análise foi estabelecido considerando alguns fatores para evitar divergências, assim a análise foi feita no sentido leste - oeste da Avenida Conde da Boa Vista, considerando todas as intersecções da direita para esquerda. FIGURA 1. 
Figura 1 - Modo de avaliação

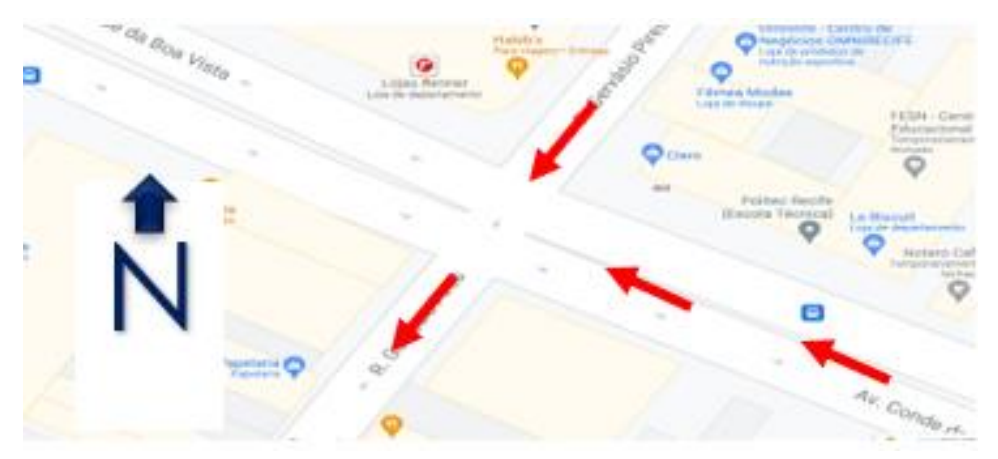

Fonte: Google Maps, adaptada pelos autores (2021)

\section{O CASO DO RECIFE E SUA INFRAESTRUTURA CICLOVIARIA NA ÁREA CENTRAL}

A cidade do Recife, é a Cidade-Sede da Região Metropolitana (RM), FIGURA 2, que de forma mais abrangente, segundo dados do IBGE (2010) ocupa a $5^{\text {a }}$ posição em relação a sua população, ficando atrás apenas das regiões metropolitanas de São Paulo (19.672.582 habitantes); Rio de Janeiro(11.711.233 habitantes); Belo Horizonte (5.413.627 habitantes); Porto Alegre (3.960.068 habitantes) e Recife (3.688.428 habitantes). O município de Recife ocupa a 9a posição com 1.536.934 habitantes.

Figura 2 - localização do município

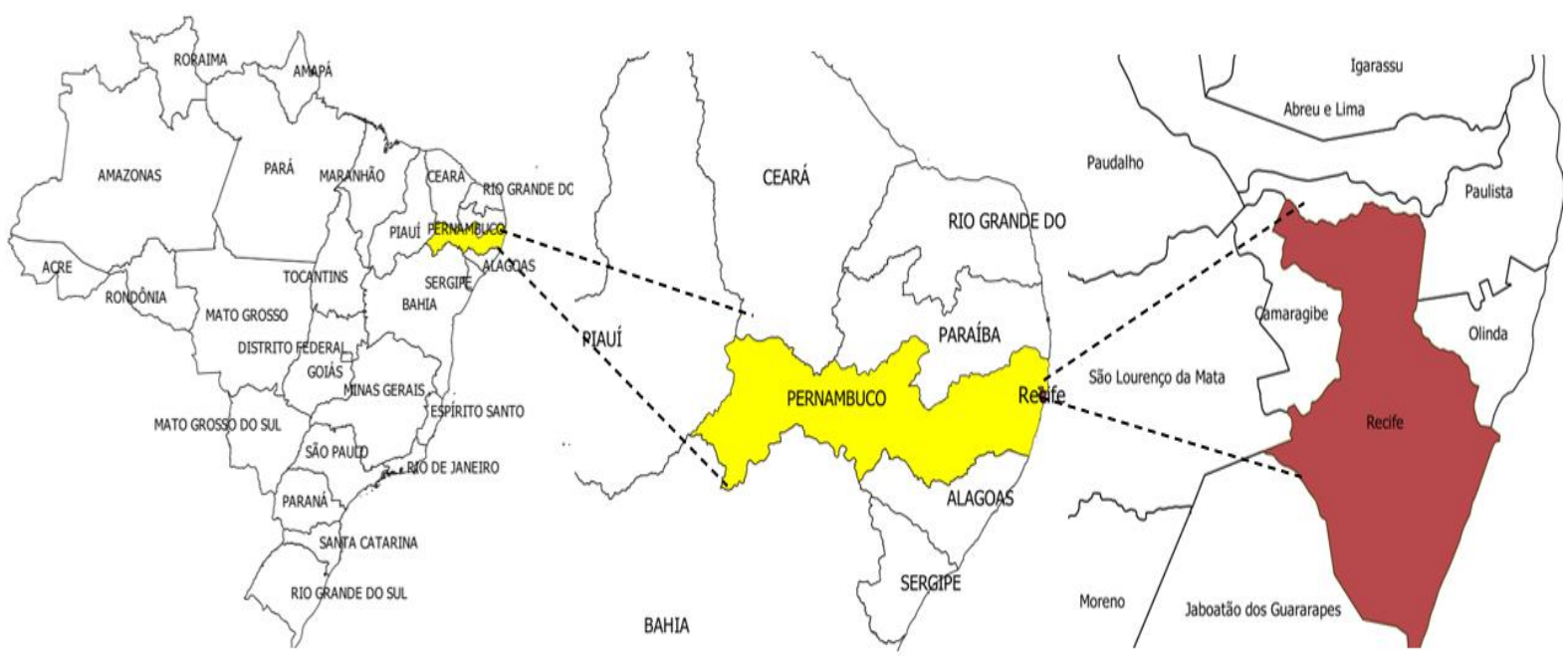

Fonte: Autores (2021)

Dada essa amplitude, a cidade é caracteriza por uma distribuição modal bastante ampla contemplando os meios de transportes públicos servidos pelo metrô, Veículo Leve sobre Trilhos (VLT) e operadoras privadas de ônibus. Quanto ao transporte privado, oferta serviços de taxi e, transporte por aplicativo. Existe ainda, há algumas décadas, a tentativa de implantação de um modal aquaviário que poderia ser exercido através do rio Capibaribe, que inclusive faz intersecção com o início da Avenida Conde da Boa Vista, conforme destacado por Silva Filho (2009), como uma alternativa para compor o transporte no município do Recife e Região Metropolitana. 
De todos os meios citados é possível dizer que existe uma malha viária razoavelmente bem distribuída, com serviços regulares e bem padronizados. No entanto, a questão é bem divergente quando nos referimos ao transporte individual não motorizado, sobretudo no tratamento com as bicicletas e sua infraestrutura.

Começando pelo ponto mais central, uma primeira área que merece ser avaliada, levando-se em consideração a estrutura cicloviária, diz respeito a estação final do metrô, pois neste ponto há também uma estação bicicletária importante, sobretudo, pelo fato de ser um elemento numa possível integração modal trata-se da estação terminal Recife que contempla dois modais, ou seja, além do modal metroviário tem-se também o modal por ônibus. A estação tem o nome estação Casa da Cultura, que compõe a estação 10. FIGURA 3.

Outro local importante situa-se a aproximadamente 300 metros, estação cicloviária 9, denominada Praça Joaquim Nabuco. FIGURA 4. Ambos são desprovidos de qualquer estrutura, ou seja, há o incentivo, mas não há estrutura mínima. Esse segundo segmento também é bastante importante e considerável, pois serve de alternativas para o acesso à Avenida Conde da Boa Vista.

Figura 3 - Entorno da estação terminal Recife

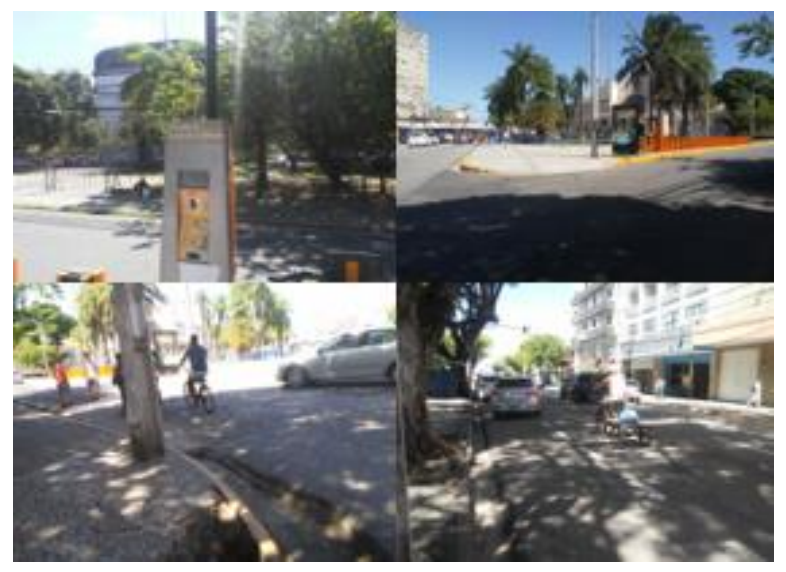

Fonte: Autores (2021)
Figura 4 - Entorno da Praça Joaquim Nabuco

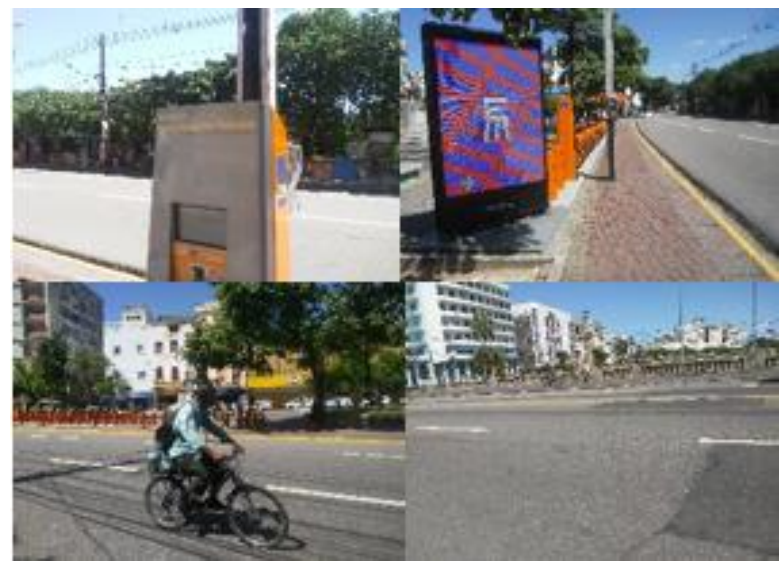

Fonte: Autores (2021)

\section{1 Avenida Conde da Boa Vista}

A presente Avenida situa-se na RPA - Região Político Administrativa: 1, que por sua vez compõe a Microrregião: 1.2, ficando distância do Marco Zero $(\mathrm{km}) 1: 2,78$. Possui área territorial (hectare)2: 176. A população residente no bairro da Boa Vista é de (Habitantes): 14.778.

A região inserida do estudo caracteriza por ser o eixo principal (estruturante) da área central, com aproximadamente 1.7 quilômetros, cortando diversas vias de acesso aos comércios e serviços do centro. Seus pontos de interseções iniciam-se na Ponte Duarte Coelho e terminam na Rua Dom Bosco, e seu prolongamento passa a se chamar Avenida Carlos de Lima Cavalcanti. Corta os bairros da Boa Vista e da Soledade.

A Avenida Conde da Boa Vista é na atualidade uma das principais vias do Recife. Uma média diária aponta que cerca de 400 mil pessoas e 9.700 veículos circulam pelo local, segundo dados da Prefeitura do Recife e 
do Grande Recife Consórcio de Transporte(2021). As figuras FIGURA 5 e 6 apresentam, respectivamente, a localização da avenida e o segmento a ser avaliado.

Figura 5 - Localização da Avenida

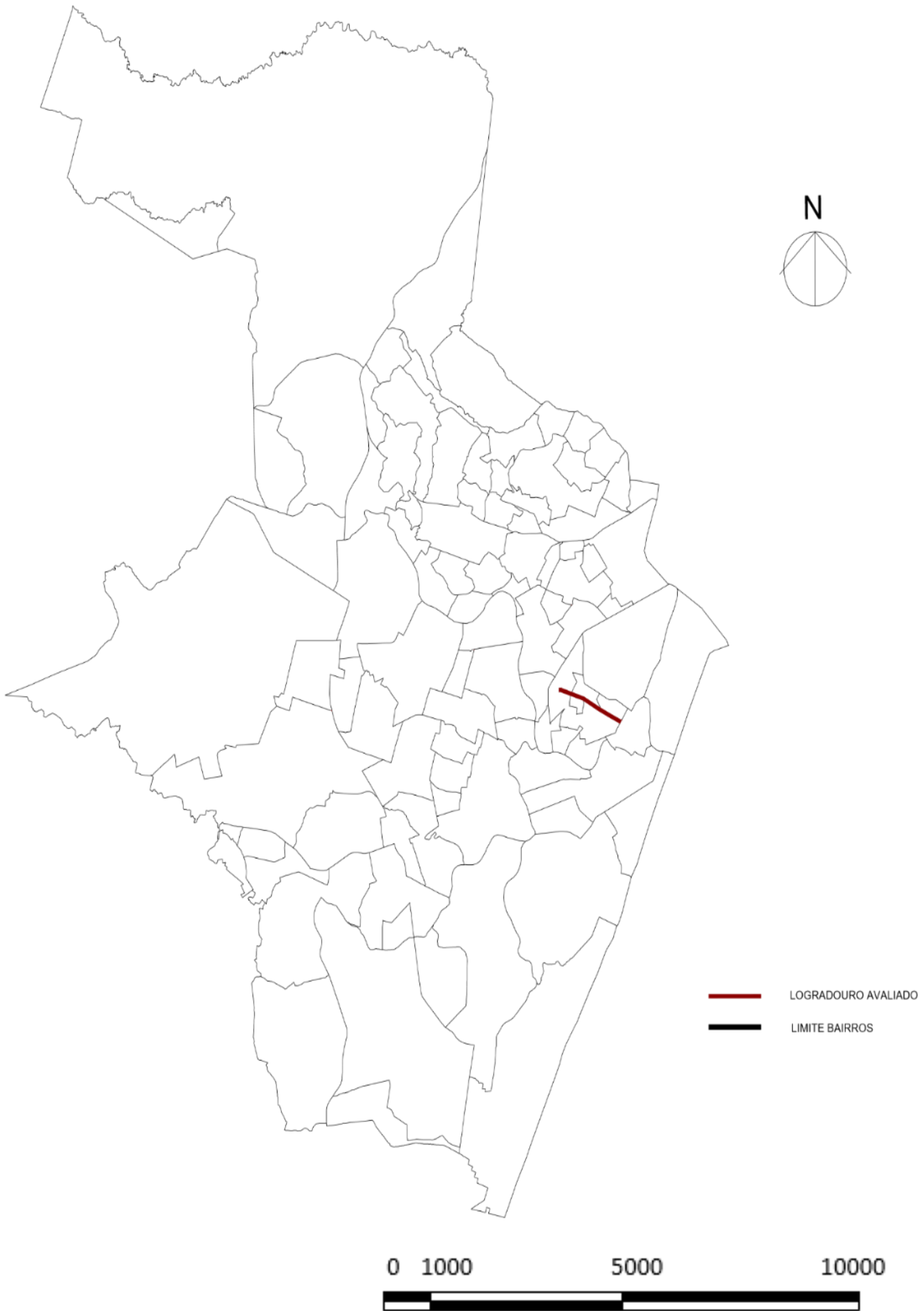

Fonte: Autores (2021) 
Figura 6 - Segmento a ser avaliado

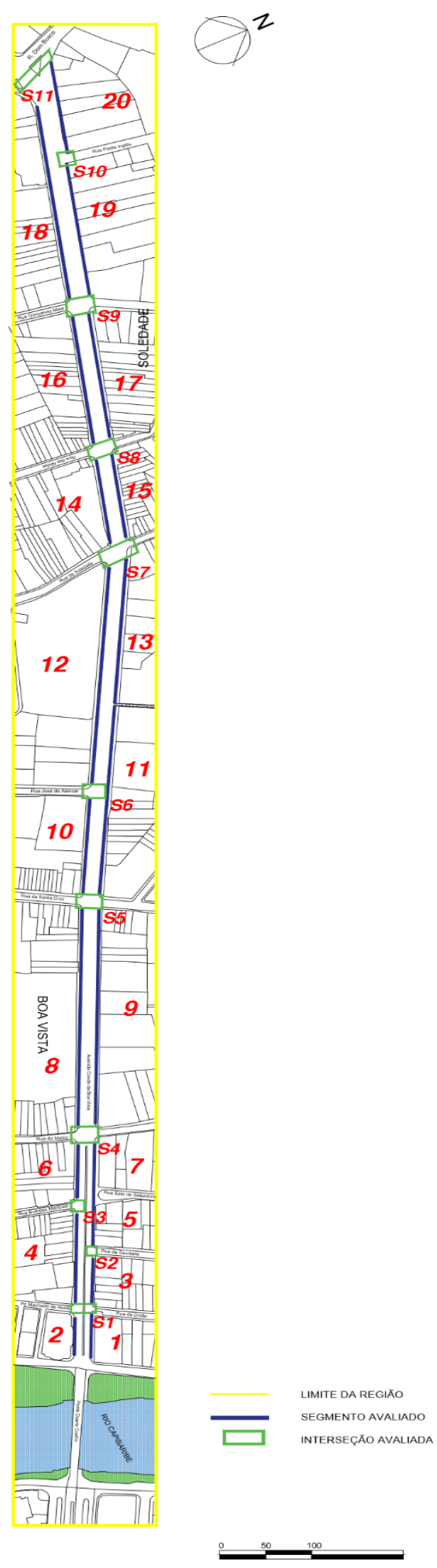

Fonte: Autores (2021) 


\section{DISCUSSÃO}

A partir das observações estabelecidas pela vistoria técnica - trabalho de campo, levantamento fotográfico - é possível observar a total ausência de infraestrutura para o modal cicloviário. As fotos da Avenida e suas intersecções foram feitas, entre os dias 05/05/20021 e 30/05/2021, no período da manhã e da tarde.

Apesar de haver certo incentivo em função do uso das bicicletas através da distribuição de algumas estações de bicicleta, não há estrutura básica ou adequada para o seu uso. Assegurar a qualidade de infraestruturas para o uso de bicicletas é uma das formas de favorecer a acessibilidade cicloviária, contribuindo assim para uma mobilidade urbana mais sustentável. Batista e Lima (2020) são enfáticos ao afirmar que, um sistema cicloviário consiste em todos os elementos de infraestrutura e de suporte para atender às necessidades dos deslocamentos através da bicicleta em meio urbano.

Para que seja eficiente, o sistema cicloviário deve ser integrado aos polos geradores de viagens, em uma rede coesa e bem distribuída na cidade, possibilitando uma mobilidade associada aos demais modos de transporte, com infraestrutura de qualidade (CARDOSO E CAMPOS, 2016). Como destacado por Andrade et al., (2016) citando vários autores, a cicloestrutura, compreendida como os espaços de infraestrutura viária dedicada ao ciclista, é importante para contribuir com aspectos, como a segurança e o conforto. Para tanto, são criados dispositivos de segregação, sinalização e outros elementos que caracterizam diferentes tipos de cicloestrutura, como a ciclovia e a ciclofaixa.

No que tange às intersecções, a primeira a ser avaliada, a Rua da Aurora, onde neste local é possível observar uma estrutura cicloviária, razoável, com atendimento às larguras mínimas e piso regular, mas ausência de segregação, o que garantiria maior segurança. No que diz respeito à sinalização da travessia pode-se dizer que é confusa por não priorizar sinalização vertical específica para os cliclistas. FIGURA 8. Depois, na sequência, tem-se a segunda intersecção, Rua da União, que se caracteriza por ausência total de estrutura cicloviária. FIGURA 9.

Figura 8 - Rua da Aurora

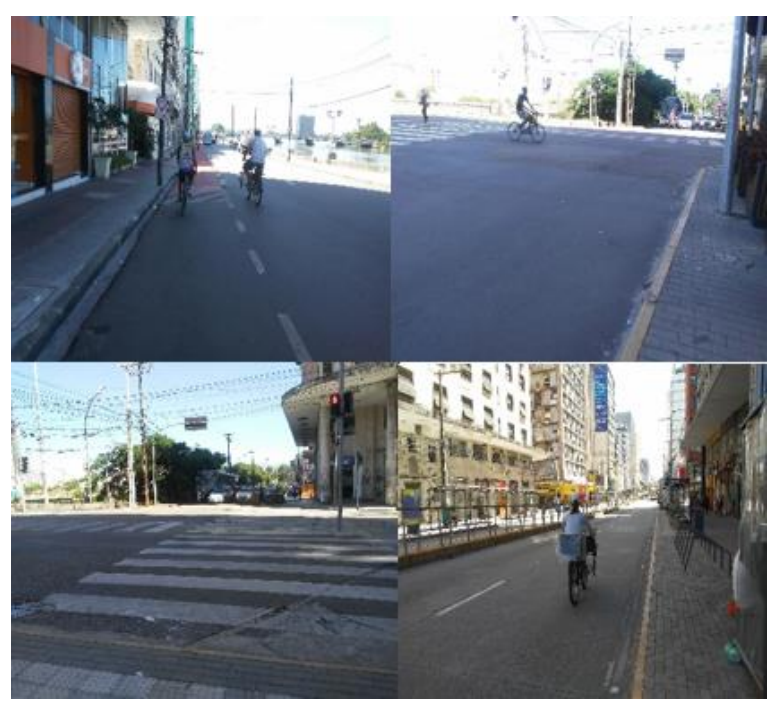

Fonte: Autores (2021)
Figura 9 - Rua da União

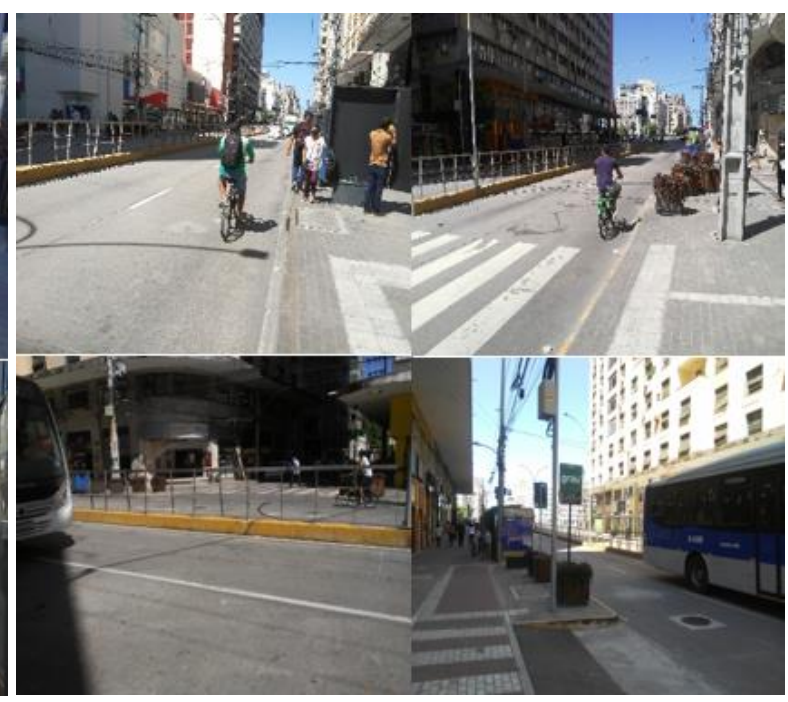

Fonte: Autores (2021) 
As duas próximas intersecções dizem respeito às Ruas da Saudade (FIGURA 10) e Sete de Setembro (FIGURA 11), respectivamente. Também total ausência de ciclofaixas, ciclovias e/ou ciclorrota e sinalização. Obrigando assim o ciclista a dividir a faixa de rolamento com o transporte público, que nessa região é servida por ônibus, através de corredor exclusivo, segregado, táxi, motocicletas e em alguns pontos, por Uber.

Figura 10 - Rua da Saudade

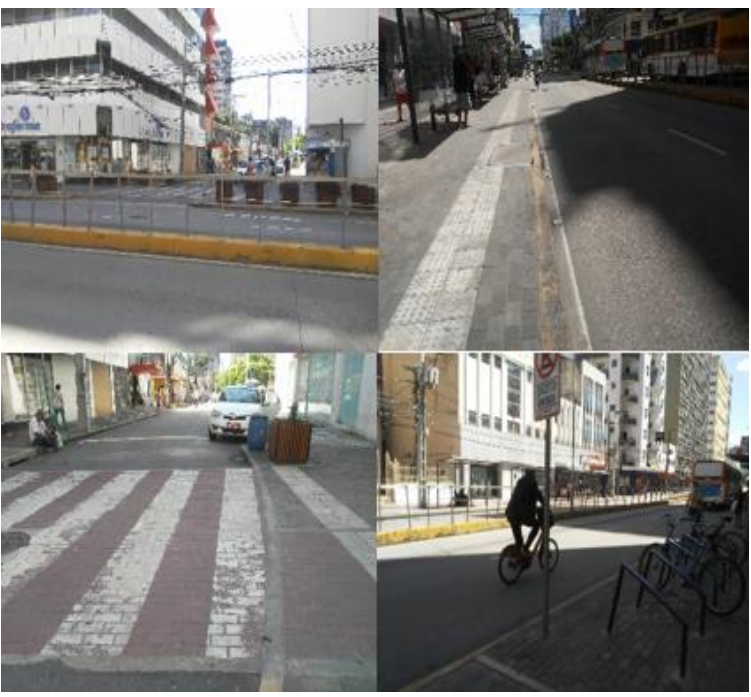

Fonte: Autores (2021)
Figura 11 - Sete de setembro

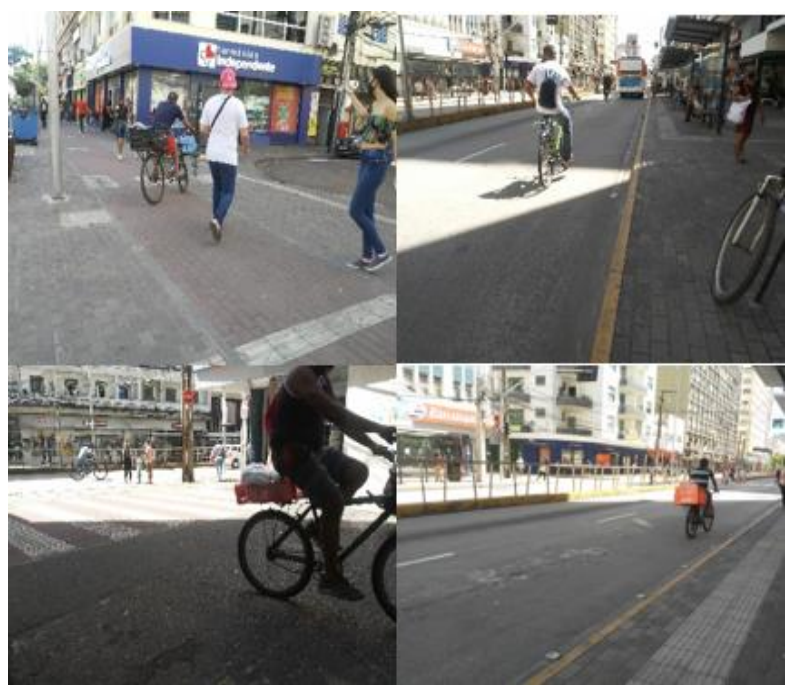

Fonte: Autores (2021)

A seguir são analisadas mais duas ruas que se cruzam com a Avenida Conde da Boa Vista, a primeira tratase da Rua do Hospício, que apresenta uma estrutura também muito mínima e bem precária, bastante estreita, piso irregular e falta de sinalização adequada. FIGURA 12. Já a segunda diz respeito a Rua Gervásio Pires, com total ausência de estrutura cicloviária. FIGURA 13.

Figura 12 - Rua do Hospício

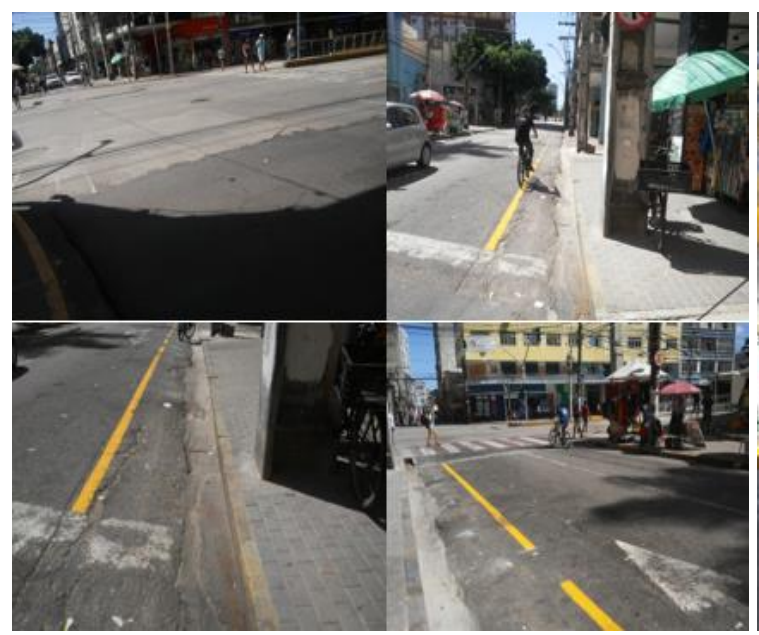

Fonte: Autores (2021)
Figura 13 - Rua Gervásio Pires

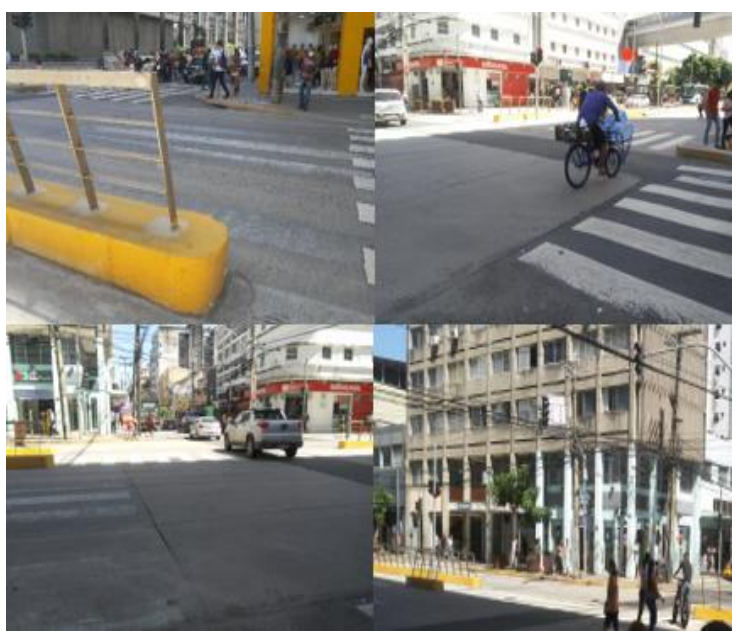

Fonte: Autores (2021) 
A seguir, tem-se a Rua José de Alencar, FIGURA 14, que tem uma ciclofaixa bem sinalizada, com uma largura considerável, mas não segregada. Já a Rua da Soledade tem uma estação, chamada estação da Soledade 27, mas não dispõe de estrutura nos entornos da estação. Com a dificuldade acentuada, inclusive para a retirada da bicicleta na estação pelo fato de estar bastante próxima aos carros na faixa de rolamento. FIGURA 15.

Figura 14 - Rua José de Alencar

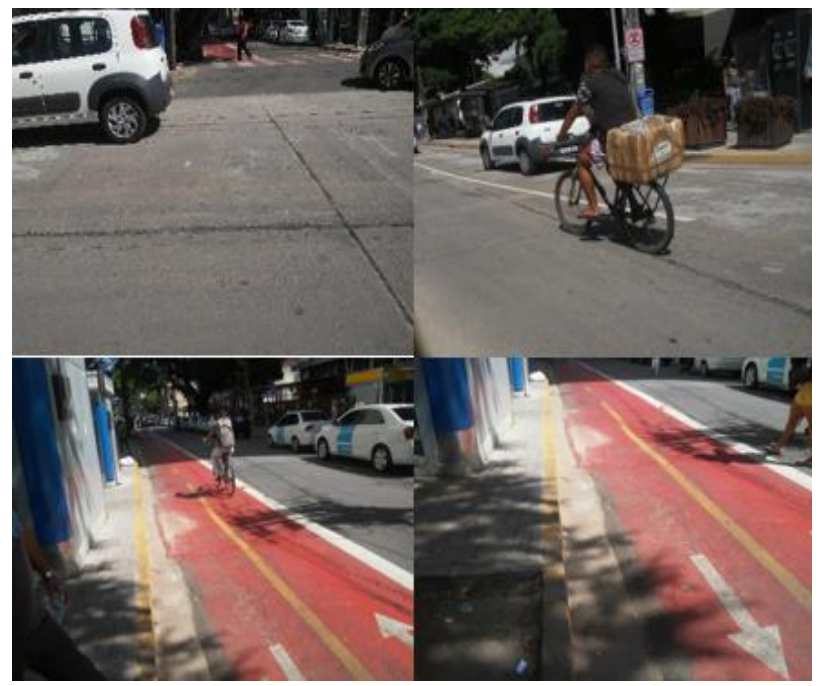

Fonte: Autores (2021)
Figura 15 - Rua da Soledade

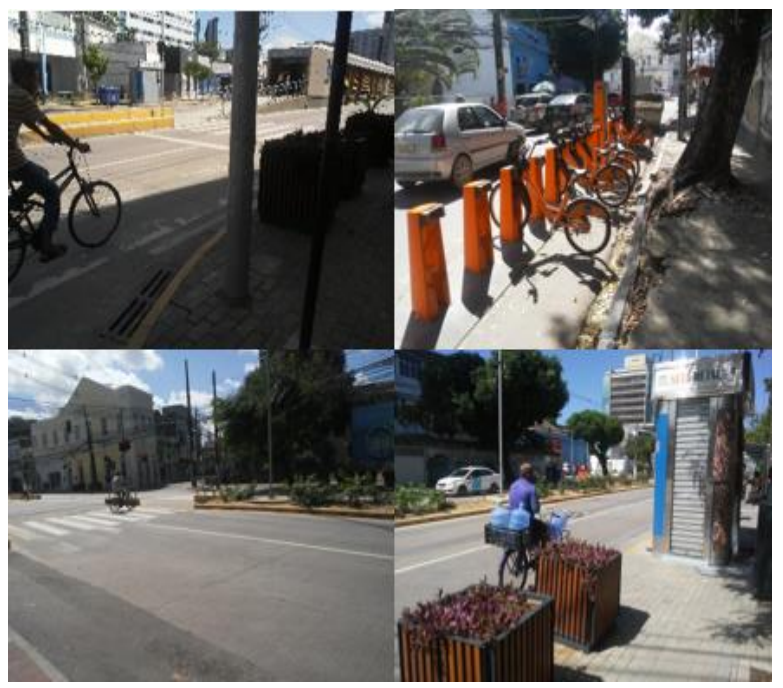

Fonte: Autores (2021)

A seguir, tem-se, a Rua das Ninfas e Rua Osvaldo Cruz, com total ausência de infraestrutura, conforme pode ser observada. FIGURA 16 e FIGURA 17.

Figura 16 - Rua das Ninfas

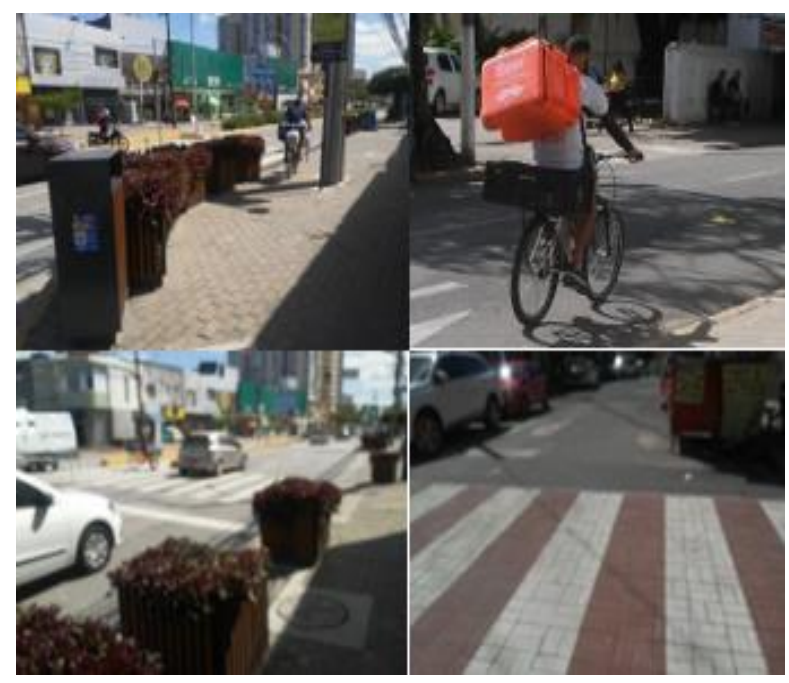

Fonte: Autores (2021)
Figura 17 - Rua Osvaldo Cruz

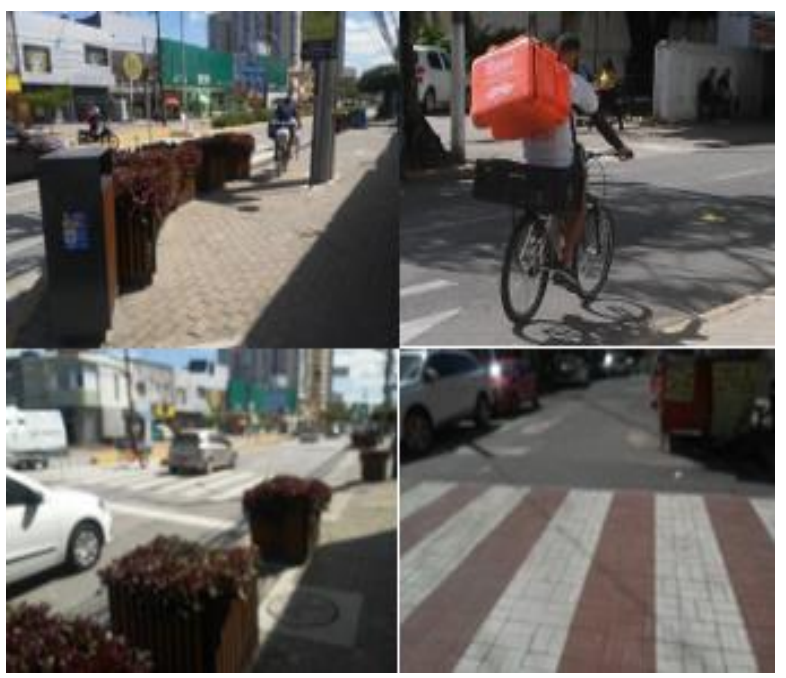

Fonte: Autores (2021) 
Por fim, tem-se as duas últimas intersecções objetos de análises, as Ruas Padre Inglês FIGURA 18 e Rua Dom Bôsco FIGURA 19, ambas também como a maioria das ruas analisadas não apresentam qualquer estrutura para os ciclistas. No caso específico da FIGURA 18 a questão é mais contundente por se tratar de uma rua com característica de avenida, ou seja, faz intersecção com importantes eixos de circulação da área central do recife, a exemplo da Avenida Agamenon Magalhaes.

Figura 18 - Rua Padre Inglês

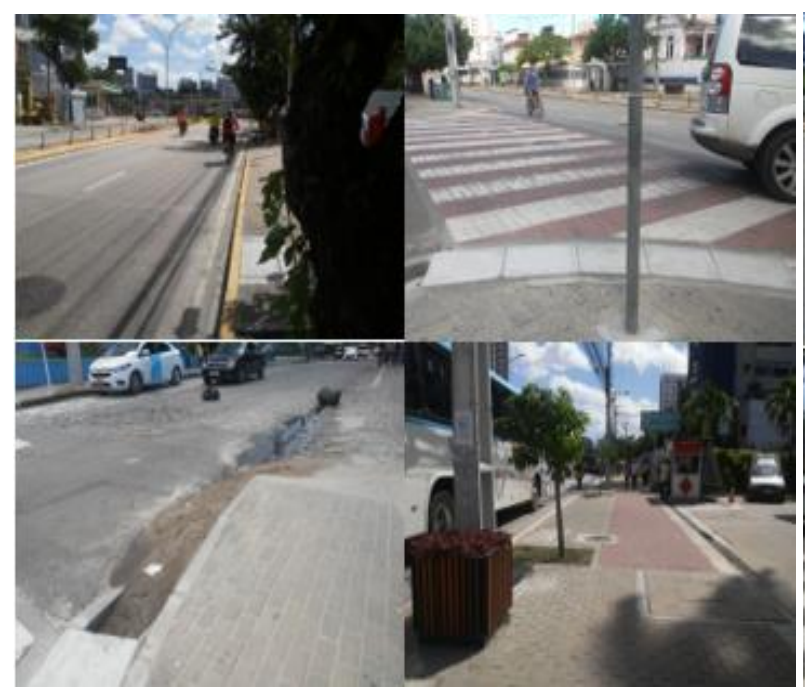

Fonte: Autores (2021)
Figura 19 - Rua Dom Bôsco

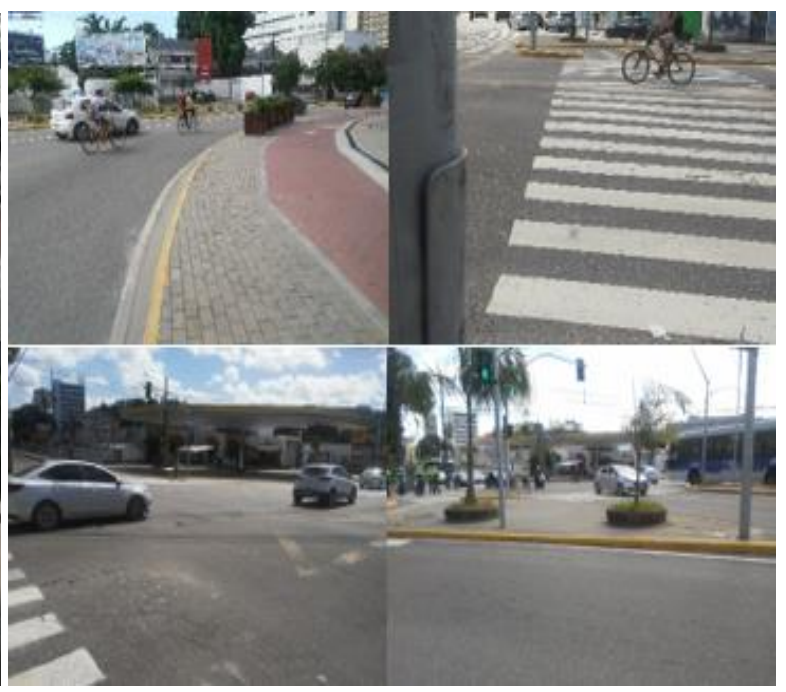

Fonte: Autores (2021)

No tocante a Avenida Conde da Boa Vista em si, foi possível observar um fluxo bastante elevado, sobretudo de ciclistas que fazem deslocamento para atendimento de seus trabalhos - exemplos das bicicletas de carga. Entre 2007 e 2008, a avenida sofreu modificações no seu corredor viário, passando a fazer parte do chamado Corredor Leste-Oeste, um corredor exclusivo de ônibus, juntamente com a Avenida Caxangá e a Rua Benfica. A sua estrutura de circulação é composta por vias de acesso exclusiva ao transporte público e por serviços de táxi, e a outra parte serve para o deslocamento do transporte privado (automóveis e motocicletas), dá acesso também a diversos serviços hospitalares (público e privado), seus passeios e calçadas são bastante conservados e apropriado ao pedestre em geral.

Entretanto, quando a questão é a infraestrutura para bicicletas, a sua função, em detrimento desse conceito de mobilidade urbana sustentável é bastante polêmica e contundente, pois não há nenhuma estrutura para este modal, ou seja, quase que total ausência de ciclovias, ciclofaixas e ciclorrotas. O mais agravante diz respeito ao fato de que a maioria dos ciclistas que dividem o espaço com os veículos motorizados, é para execução de prestação serviços tanto de entrega representados pelos trabalhadores, quanto de estudantes, pois a avenida também é dotada de escolas e faculdades.

\section{CONCLUSÕES}

De modo geral, devido a diversos fatores como, os fatores econômicos, sociais, ambientais e de qualidade de vida, as necessidades de deslocamento através do modal exercido por bicicletas aumentou substancialmente, sobretudo nas médias e grandes cidades brasileiras. Tal fenômeno sinaliza para melhores condições de infraestrutura. Aliado a isto, o segmento populacional que faz uso deste modal está entre os 
grupos modais mais vulneráveis no uso dos sistemas de transporte urbano, resultando em acidentes muitas vezes com vítimas fatais.

De modo específico, motivados por esses aspectos, estabeleceu-se um estudo em uma área central da cidade do Recife (Avenida Conda da Boa Vista). Comprovou-se a assertiva de que se por um lado há diversas estações de bicicletas, por outro lado é evidente a falta de infraestrutura para os deslocamentos dos usuários deste modal. De todas as intersecções analisadas num total de 12 e considerando a avenida em si, apenas 3 apresentaram uma estrutura mínima, entretanto dessas 3, apenas 2 tinham a largura padrão e, dessas 2 apenas uma tinha a sinalização adequada, caso demonstrado na FIGURA 13.

Por fim, esta pesquisa não tem por intenção esgotar a discussão sobre o assunto, pelo contrário, espera-se que estas e outras questões pontuais, no que tangem os deslocamentos e circulação dentro do espaço urbano, sejam mais e melhores abordadas, para que o poder público possa intervir em ações específicas. Espera-se ainda, que todo esforço debruçado nessa pesquisa seja de bastante proveito e valia para os usuários de transporte não motorizado - bicicletas - e para a sociedade com um todo.

\section{REFERÊNCIAS} $2002 b$.

. NBR 10520: Informação e documentação - Citações em documentos - Apresentação. Rio de Janeiro,

ABRACICLO. Associação Brasileira Fabricantes de Motocicletas, Ciclomotores, Motonetas, Bicicletas e similares, 2004.

ANDRADE, A.; RODRIGUES, J.; MARINO, F.; LOBO, Z. Mobilidade por bicicleta no Brasil. Rio de Janeiro: PROURB/UFRJ, 2016.

CARDOSO, P. B.; CAMPOS, V. B. G. (2016). Metodologia para planejamento de um de sistema cicloviário. Transportes, 24(4), 39-48.

Batista, D. G. P., \& Lima, E. R. V. (2020). Índice de avaliação da qualidade de infraestruturas cicloviárias: um estudo em João Pessoa-PB. urbe. Revista Brasileira de Gestão Urbana, 12, e20190086. https://doi.org/10.1590/2175- 3369.012.e20190086.

FEDER, M. Ciclofaixas - análise da legislação e das normas brasileiras. Revista dos Transportes Públicos -

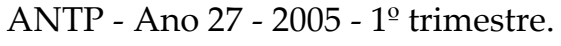

GEIPOT. Planejamento cicloviário: diagnóstico nacional, Empresa Brasileira de Planejamento de Transportes, Ministério dos Transportes, Brasília, BR, 2001a.

GEIPOT, Manual de planejamento cicloviário, Empresa Brasileira de Planejamento de Transportes, Ministério dos Transportes, Brasília, BR, 2001b.

GIL, A. C. Métodos e técnicas de pesquisa social. 6. ed. São Paulo: Atlas, 2008. 
INSTITUTO BRASILEIRO DE GEOGRAFIA E ESTATÍSTICA (IBGE). População nos Censos Demográficos, segundo os municípios das capitais - 1872/2010. Disponivel em: https://censo2010.ibge.gov.br/sinopse/index.php?dados=6. Acesso: 02 de julho, 2021.

LITMAN, T., Quantifying the benefits of nonmotorized transport. Transport Policy Institute VTPI, USA, 1999.

MINISTÉRIO DAS CIDADES. Política Nacional de Mobilidade Urbana Sustentável. Caderno 6, novembro, 2004.

MIRANDA, A. C. M., Palestra, visão global do uso de bicicletas e sua integração com o transporte público, Porto Alegre, BR, 2004.

NEVES, P. B. T. Proposta de padrão de tratamento cicloviário e experiência da cidade de Belém, Congresso Brasileiro de Transporte e Trânsito, 14/10, Anais: ANTP, 2003. 1 CD-ROM, Vitória, BR, 2003.

PEZZUTO, C. C.; SANCHES, S. P., Por que as bicicletas são pouco utilizadas nas cidades brasileiras de porte médio, Congresso Brasileiro de Transporte e Trânsito, 14/10, Anais: ANTP, 2003. 1 CD-ROM, Vitória, BR, 2003.

POPPER, K. R. A ciência normal e seus perigos. In: LAKATOS, Imre; MUSGRAVE, Alan (Org.). A crítica e o desenvolvimento do conhecimento. São Paulo: Cultrix, 1979.

Prodanov, Cleber Cristiano. Metodologia do trabalho científico [recurso eletrônico] : métodos e técnicas da pesquisa e do trabalho acadêmico / Cleber Cristiano Prodanov, Ernani Cesar de Freitas. - 2. ed. - Novo Hamburgo: Feevale, 2013.

RECIFE. Prefeitura da Cidade. Serviços para o cidadão - Bairro da Boa Vista. Disponível em: http://www2.recife.pe.gov.br/servico/boa-vista. Acesso em 10/05/2021.

ROESCH, S. M. A. Projetos de estágio e de pesquisa em administração: guia para estágios, trabalhos de conclusão, dissertações e estudos de caso. 2. ed. São Paulo: Atlas, 1999.

RUBIM, B.; LEITAO, S. O plano de mobilidade urbana e o futuro das cidades. Estud. av. São Paulo, v. 27, n. 79, p. 55-66, 2013.

SILVA FILHO, N. G. O Rio Capibaribe como Alternativa para o Transporte Urbano: Ecologicamente Sustentável e Socialmente Inclusivo. UFPE, Recife, Brasil. ELECS 2009 - Edificações e Comunidades Sustentáveis, Recife:José Jeferson Rêgo Silva \& Miguel Aloysio Satler, 28-30 de outubro, Recife, ANTAC, 2009, 2009 v. 624.

SILVA FILHO, N. G.; RAIA JUNIOR, A. A. Do discurso prático à prática discursiva: a mobilidade urbana e seu contexto sociopolítico. Contradições e lacunas entre a elaboração e execução do planejamento das políticas de transporte nas cidades brasileiras - o caso da Região Metropolitana do Recife (RMR). Labor e Engenho, Campinas, SP, v. 10, n. 